\title{
ARQUIVOS, RASTROS E HISTÓRIA A PRESENÇA DE DARCY AZAMBUJA NA REVISTA PROVÍNCIA DE SÃO PEDRO
}

\author{
Margarete Jesusa Varela Centeno Hülsendeger \\ PUC/RS - CAPES
}

RESUMO: Os arquivos são um corpo organizado de documentos que mantém relação com uma instituição, resultado de uma atividade profissional ou sendo produzidos ou recebidos por essa mesma instituição, tornando-se documentos conservados. Assim, ao frequentar os arquivos, ao consultar documentos, 0 historiador se propõe a rastrear 0 passado, deparando-se, muitas vezes, com regiões silenciosas capazes de levar a outras narrativas históricas que valorizam o não dito. Com base nesses pressupostos, neste artigo, analisa-se a trajetória do escritor e jurista gaúcho Darcy Azambuja como colaborador da revista literária Província de São Pedro, assim como, discute-se a sua presença (ou ausência) na obra A História da Literatura do Rio Grande do Sul (1956), do historiador Guilhermino Cesar. Desse modo, além de recuperar-se um pouco da história da Província de São Pedro, rastreia-se a participação de Azambuja, não só nesta revista, mas também no cenário da história literária rio-grandense.

PALAVRAS-CHAVE: Província de São Pedro. Darcy Azambuja. História da literatura.

\section{ARCHIVES, CLUES AND HISTORY \\ THE PRESENCE OF DARCY AZAMBUJA \\ IN THE PROVINNCIA DE SÃO PEDRO MAGAZINE}

ABSTRACT: Archives are an organized body of documents related to an institution, resulting from a professional activity, or are produced or received by this same institution, thus becoming preserved documents. When dwelling into archives and checking documents, the historian proposes to track the past, often facing silent regions that can take one to other historical narratives, some of which value the unsaid. Based on these assumptions, this paper analyses the trajectory of the writer and jurist Darcy Azambuja as contributor to the literary magazine Província de São Pedro, and debates his presence (or his absence) in A História da Literatura do Rio Grande do Sul (1956), by the historian Guilhermino Cesar. In this way, recovering some of the history of the Província de São Pedro Magazine, this paper addresses the participation of Azambuja not only in the magazine, but also in the literary history scene of Rio Grande do Sul.

KEYWORDS: Província de São Pedro. Darcy Azambuja. Literary history.

de Letras/PUCRS.

é Doutoranda em Teoria da Literatura da Faculdade 


\section{ARQUIVOS, RASTROS E HISTÓRIA A PRESENÇA DE DARCY AZAMBUJA NA REVISTA PROVÍNCIA DE SÃO PEDRO ${ }^{1}$}

\section{Margarete Jesusa Varela Centeno Hülsendeger}

INTRODUÇÃO

Quando um historiador se propõe a narrar um acontecimento ele deve ter consciência de que sua narrativa também será composta por "regiões silenciosas", ou seja, acontecimentos deixados de lado em subordinação a outros que serão realçados. Aliás, as explicações das estruturas e dos processos históricos são determinadas, geralmente, pelo que será deixado de fora das nossas representações. ${ }^{2}$

Se o objeto de análise é a literatura, pode-se observar esse fenômeno ocorrendo tanto para obras como para autores. No entanto, faz parte da tarefa do historiador analisar as causas dessas omissões, podendo-se também, a partir delas, construir outra narrativa histórica que valorize o que não foi dito, pois os mortos, não podendo mais se pronunciar, precisam que alguém Ihes dê voz e espaço para se fazerem conhecidos. Afinal, "O discurso sobre o passado tem como estatuto ser o discurso do morto." ${ }^{3}$

Do mesmo modo, é preciso lembrar que "nenhum conjunto de eventos atestados pelo registro histórico compreende uma estória manifestamente acabada e completa." ${ }^{4}$ Assim, as "verdades históricas" foram substituídas pelas "verdades narrativas" e "se a narrativa do passado é seletiva e secular não significa que ela seja falsa, porque se admitirmos isso, o único relato fiel do passado seria o próprio passado, e não o veríamos como história." ${ }^{5}$ Assim, quando se constrói uma história da literatura é preciso ter a consciência de

\footnotetext{
${ }^{1}$ Este artigo é o resultado de uma pesquisa realizada para disciplina de Historiografia da Literatura Brasileira, ministrada pelas professoras doutoras Maria Eunice Moreira e Regina Kohlrausch, com material retirado do acervo DELFOS/PUCRS.

${ }^{2}$ WHITE, Hayden. Trópicos do discurso: ensaios sobre a crítica da cultura. Trad. Alípio Correia de Franca Neto. São Paulo: EDUSP, 1994.

${ }^{3}$ CERTEAU, Michel de. A escrita da história. Trad. Maria de Lourdes Menezes. Revisão técnica Arno Vogel. Rio de Janeiro: Forense Universitária, 1982, p. 55.

${ }^{4}$ WHITE, Hayden. Trópicos do discurso: ensaios sobre a crítica da cultura, op. cit., p. 106.

${ }^{5}$ PERKINS, David. História da literatura e narração, Cadernos do Centro de pesquisas Literárias da PUCRS, Porto Alegre, v. 3, n. 1, março, 1999, p. 9. (Série Traduções).
} 
que os dados que a constituem são sempre itens interpretados e avaliados; portanto, não são fatos dados objetivamente. ${ }^{6}$

Tendo como base o pressuposto de que uma história literária é intrinsecamente seletiva, arbitrária e incompleta, o objetivo, deste trabalho, é analisar a participação do escritor, jurista e professor Darcy Azambuja (19031970) como colaborador da revista literária Província de São Pedro (19451957). Além disso, discute-se a sua presença (ou ausência) na obra A História da Literatura do Rio Grande do Sul (1956), do historiador e crítico literário Guilhermino Cesar (1908-1993).

\section{A PROVÍNCIA DE SÃo PEDRO}

Em junho de 1945 ocorria o lançamento da revista Província de São Pedro uma publicação da Livraria do Globo, de Porto Alegre. Seu editor, durante os seus 12 anos de existência, foi o jornalista, político e escritor gaúcho Moysés Vellinho (1902-1980).

Em seu primeiro editorial, Vellinho deixa claro quais seriam os objetivos da revista: "... não afogar-se nas águas rasas da retórica regionalista", mas promover, no Rio Grande do Sul, "as obras de inteligência". Ele também prometia resguardar a revista dos "perigos do tradicionalismo estreito e das pieguices do saudosismo." Segundo Vellinho, o propósito da Província de São Pedro era manter em evidência "os temas e motivos da formação rio-grandense e de sua evolução dentro dos limites maiores da nacionalidade."7 Para que tais objetivos fossem alcançados a revista contou com a colaboração de diversos e qualificados escritores, jornalistas, críticos, poetas, filósofos e historiadores.

A intenção de manter em evidência "os temas e motivos da formação riograndense" já se manifestou no segundo editorial da Província (setembro de 1945) quando, aproveitando as comemorações do centenário da Revolução Farroupilha, Vellinho exaltou o espírito, ao mesmo tempo, guerreiro e liberal do povo gaúcho. Ao lembrar o tratado de Poncho Verde, escreve que até mesmo Duque de Caxias compreendia que "aqueles homens poderiam estar

\footnotetext{
${ }^{6}$ SCHMIDT, Siegfried J. Sobre a escrita de histórias da literatura. Observações de um ponto de vista construtivistas. In: OLINTO, Heidrun Krieger. Histórias de literatura. As novas teorias alemãs. São Paulo: Ática, 1996, p. 101-131.

7 Província de São Pedro. In: MOTTIN, Antônio João Silvestre et al. Revista Província de São Pedro / 1945/57: catálogo e texto. Porto Alegre: PUCRS, 1999. CD-ROM.
} 
errados, mas era preciso respeitá-los como brasileiros." ${ }^{8}$ Moysés Vellinho conclui o editorial desse segundo número afirmando que "os homens só têm uma maneira de alcançar o respeito uns dos outros: é pagando, pontualmente, o seu preço pela liberdade." ${ }^{\prime \prime}$

Dois anos após o primeiro editorial, Vellinho acredita que - apesar da preocupação inicial de que a revista pudesse ser vista como uma "exacerbação regionalista", despertando suspeitas e mal-entendidos - a Província atingiu os seus objetivos. Segundo ele, houve, da parte de diferentes críticos, jornalistas, poetas, escritores, sociólogos e romancistas, o devido reconhecimento da qualidade literária da publicação. A revista, na voz de seu editor, reafirmou a ideia de "que a cultura brasileira não deve ser orientada em favor de sua centralização, mas, pelo contrário, precisa-se alastrar-se, ganhar espaço dentro do Brasil, porque assim o reclamam urgentes imperativos sociais e políticos." ${ }^{10} \mathrm{Ele}$ termina esse editorial "festivo" declarando, "Uma revista como a Província de São Pedro, de puro interesse cultural, não precisa, para viver, senão do agasalho do espírito, fruto dessa generosa compreensão."11

Para Guilhermino Cesar,

[...] a maior virtude de nossa vida literária provinciana tem sido a profunda identidade de pensamento, dos homens que a constituíram, com o seu povo, sendo a opção a regra e a disponibilidade a exceção. E no Rio Grande, de modo particular, verifiquei essa presença viva do homem de letras, em todos os movimentos da alma coletiva. ${ }^{12}$

Nesse sentido, a Província de São Pedro, contando com as colaborações de autores oriundos de diferentes áreas do saber e de diversas partes do país, demonstrou que a cultura rio-grandense, mesmo não abrindo mão de sua identidade, fazia parte de um contexto maior, no qual a sua literatura tinha um espaço garantido. Para ratificar essa posição, Vellinho (no editorial de junho de 1945), vale-se, inclusive, de uma citação do jornalista, advogado, professor e crítico literário pernambucano Álvaro Lins (1912-1970): o escritor "será tanto mais nacional quanto mais for um produto da sua região; será tanto mais

8 Ibidem.

9 Ibidem.

10 lbidem.

${ }^{11}$ Província de São Pedro. In: MOTTIN, Antônio João Silvestre et al. Revista Província de São Pedro / 1945/57: catálogo e texto, op. cit.

12 CESAR, Guilhermino. História da literatura do Rio Grande do Sul (1737-1902). Porto Alegre: Globo, 1971, p. 15-16. 
espiritual quanto mais se alimentar da inspiração que vem da terra e dos seres ligados à terra." ${ }^{\text {"13 }}$

Analisando as opiniões de Moysés Vellinho e Guilhermino Cesar a respeito do papel da literatura rio-grandense, é possível notar que ambos defendem uma literatura que se identifique com o homem da terra sem esquecer, no entanto, seu caráter nacional. Em História da Literatura do Rio Grande do Sul, Cesar admite que um exame mais miudamente crítico o convenceu "de que a literatura rio-grandense, ao contrário do que se pensa, jamais deixou de participar de todas as correntes válidas da literatura nacional." 14 Porém, estranhamente, apesar da semelhança de princípios dos dois posicionamentos, Cesar não faz nenhuma referência à Província de São Pedro, mesmo ela estando em circulação desde 1945 e ele tendo sido seu colaborador, escrevendo críticas sobre obras brasileiras.

Essa omissão pode ser justificada se levarmos em conta o fato de que a história literária escrita por Guilhermino Cesar se ocupa de um espaço bem delimitado no tempo, iniciando em 1737 e terminando em 1902. Assim, considerando apenas as datas limites de sua narrativa parece claro que a revista Província de São Pedro não poderia constar em sua análise. Cesar, quem sabe, preocupado com esses possíveis esquecimentos, explica que: "Num livro como este, as repetições são inevitáveis, até mesmo necessárias. As omissões, deliberadas umas, involuntárias outras, não desfiguram, porém, o essencial." ${ }^{\text {"15 }}$

A declaração de Cesar de que "omissões deliberadas umas, involuntárias outras" podem ter ocorrido está de acordo com a ideia de que o partidarismo é comum nas histórias literárias. Afinal, os "desejos"16 do historiador também têm seu papel na narração de histórias da literatura. Eles determinam uma "intenção organizadora" que justifica omissões e ênfases porque, para um historiador, qualquer narrativa parecerá sempre incompleta e, de certa forma,

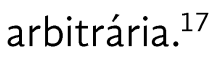

Contudo, também é possível seguir outra linha de pensamento, perguntando-se: por que Cesar teria, então, feito referência à revista Quixote, publicada em 1947 (1947-1952), dois anos após o início da publicação da Província de São Pedro?

\footnotetext{
13 Província de São Pedro. In: MOTTIN, Antônio João Silvestre et al. Revista Província de São Pedro / 1945/57: catálogo e texto, op. cit.

${ }^{14}$ CESAR, Guilhermino. História da literatura do Rio Grande do Sul (1737-1902), op. cit., p. 21.

15 Ibidem, p. 22.

16 PERKINS, David. História da literatura e narração, op. cit.

17 Ibidem.
} 
A resposta a essa pergunta pode ser dada pelo próprio Cesar quando, a propósito de caracterizar o que chamou de "sétimo período" da literatura riograndense, escreveu:

O sétimo período (1925 em diante) vem até nossos dias, até pelo menos ao aparecimento da revista Quixote (1947), onde uma nova geração, regionalista por um lado, universalista por outro, lança em foco nomes de certa importância, menos pelo que têm realizado do que pela inquietação que anunciam. ${ }^{18}$

A "intenção organizadora" parece indicar o caminho escolhido pelo historiador. Aparentemente, para Cesar, a Província de São Pedro não apresentava as características de uma publicação comprometida com o futuro. Ela não vivia o mesmo dilema que se notava nos escritores que contribuíam para a revista Quixote: "Surge o dilema: implantação de novo processo literário ou o regresso ao regional." ${ }^{19}$ Além disso, Cesar tinha uma estreita ligação com os jovens escritores da Quixote, tendo sido, inclusive, mentor de muitos deles. Como explica Michel de Certeau: "Não existe relato histórico no qual não esteja explicitada a relação com um corpo social e com uma instituição do saber." ${ }^{20}$ Questões subjetivas que, na análise de uma história da literatura, não podem deixar de ser consideradas, pois elas influenciam de maneira significativa a forma como o historiador interpretará os dados que deram origem a sua narrativa.

De qualquer maneira, determinar as razões que levaram Cesar a "esquecer" a Província de São Pedro, enquanto valorizou a revista Quixote pode se tornar um espaço fecundo para pesquisas que desejem estabelecer com mais clareza os pontos de convergência e divergência entre essas duas publicações. No momento, é possível afirmar que a Província de São Pedro foi uma revista longeva (12 anos, 21 números), algo raro não só em sua época, mas também nos dias de hoje. Nas palavras de Alice Campos Moreira, organizadora do projeto "Revista Província de São Pedro", do curso de pósgraduação em Letras da PUCRS, a Província "tinha como finalidade coligir, estimular e difundir as atividades e realizações da vida cultural do Rio Grande do Sul, fazendo-o dentro de um espírito de afirmação nacional." Do mesmo modo, segundo ela, "Moysés Vellinho foi o primeiro que conseguiu, mesmo que por um curto período, afirmar a intelectualidade gaúcha no cenário

\footnotetext{
${ }^{18}$ CESAR, Guilhermino. História da literatura do Rio Grande do Sul (1737-1902), op. cit., p. 20. 19 Ibidem, p. 20.

${ }^{20}$ CERTEAU, Michel de. A escrita da história, op. cit., p. 93.
} 
nacional."21 Propósitos que foram mantidos até a publicação do último número em 1957.

\section{DARCY AZAMBUJA}

Segundo Paul Ricoeur, "na noção de documento, hoje, já não se dá ênfase à função de ensinamento, mas sim à de apoio, de garantia, trazida a uma história, uma narrativa, um debate." ${ }^{22}$ Partindo dessa ideia pode-se, então, considerar a internet, em particular o Google, como uma ferramenta interessante na busca de informações ou evidências para a construção de uma narrativa historiográfica. No entanto, é preciso lembrar que, como qualquer arquivo, ali também existem "zonas de silêncio". Regiões que podem determinar as "molduras" 23 sobre as quais as narrativas históricas serão construídas. Assim, se digitarmos no Google o nome de Darcy Azambuja os diversos links que aparecem dirigem o internauta quase sempre para sua obra mais conhecida, o livro "Teoria Geral do Estado", publicado em 1942, pela Editora Globo. Contudo, Darcy Azambuja foi um autor premiado pela Academia Brasileira de Letras. Seguindo seu rastro fora da internet, é possível, inclusive, descobrir que ele foi considerado durante algum tempo o sucessor de Simões Lopes Neto (1865-1916).

Em 1925, com apenas 22 anos, Darcy Azambuja publicou sua primeira obra de ficção, o livro de contos No Galpão, com o qual ganhou o prêmio da Academia. Além dessa obra, Azambuja publicou individualmente, Contos RioGrandenses (1928), A Prodigiosa Aventura (1939), Romance Antigo (1940) e Coxilhas (1956). Em todas essas obras percebe-se um estilo que oscila entre as histórias ambientadas na campanha e narrativas "cujo espaço é o da incipiente Porto Alegre dos inícios do século XIX". ${ }^{24}$

Darcy Azambuja também fez parte do corpo de autores da revista Província de São Pedro. Contribuiu nos anos de 1945, 1946, 1947, 1953 e 1955 com um ensaio, cinco contos e uma crônica. Os contos reapareceriam em 1956, em sua última obra de ficção — Coxilhas —, enquanto a crônica teria sido resultado

${ }^{21}$ Província de São Pedro. In: MOTTIN, Antônio João Silvestre et al. Revista Província de São Pedro / 1945/57: catálogo e texto, op. cit.

22 RICOEUR, Paul. Tempo e narrativa - Tomo III. Trad. Roberto Leal Ferreira. Revisão técnica Maria da Penha Vilela-Petit. Campinas, SP: Papirus, 1997, p. 197.

${ }^{23}$ SCHMIDT, Siegfried J. Sobre a escrita de histórias da literatura. Observações de um ponto de vista construtivistas, op. cit.

${ }^{24}$ BAUMGARTEN, Carlos Alexandre. Darcy Azambuja. Porto Alegre: IEL, 1989, p. 37. 
de sua pesquisa para seu primeiro e único romance, Romance Antigo.

Pode-se perceber que, mesmo com a atividade de jurista (foi ProcuradorGeral do Estado) e professor da faculdade de direito (UFRGS e PUC) ocupando a maior parte de seu tempo, Azambuja também teve um papel de destaque no universo literário do Rio Grande do Sul. Todavia, sua posição como escritor regionalista e virtual sucessor de Simões Lopes Neto foi perdendo importância ao longo do tempo. Atualmente, apenas a figura do jurista e professor Darcy Azambuja ainda permanece presente nas páginas da história rio-grandense.

Para Paul Ricoeur, "qualquer rastro deixado pelo passado se torna um documento para o historiador, desde que ele saiba interrogar seus vestígios e questioná-los. [...] O que guia o interrogatório do historiador é a própria temática escolhida por ele para guiar a sua pesquisa." ${ }^{25}$ Logo, cabe ao historiador, por exemplo, perguntar: qual o significado do esquecimento? $\mathrm{E}$, no caso específico de Darcy Azambuja, questionar: porque sua obra não permaneceu como parte importante da história literária do Rio Grande do Sul? Ou ainda, mais simplesmente, inquirir: por que o escritor Darcy Azambuja foi esquecido?

Talvez não seja possível responder a essas perguntas, mas o fato é que o rastro existe, e, existindo, torna-se documento. Do mesmo modo, é importante salientar que o critério para aceitação ou rejeição de histórias literárias não é a "objetividade" ou a "verdade", mas a "plausibilidade", a "aceitabilidade intersubjetiva" e o "interesse" daqueles grupos sociais que aceitam histórias literárias como uma leitura válida. ${ }^{26}$ Portanto, mesmo que o rastro seja frágil, é preciso conservá-lo intacto, pois será ele que orientará a busca, a investigação e a pesquisa. ${ }^{27} \mathrm{E}$ foi esse rastro, frágil e tênue, que foi seguido para escrever este artigo.

\section{Darcy Azambuja e a revista Província de São Pedro}

Segundo Guilhermino Cesar,

Pode-se escrever sobre Molière sem sair de casa, ou no máximo indo consultar a biblioteca do vizinho. Mas acerca dos autores rio-grandenses, isso não é possível.

\footnotetext{
${ }^{25}$ RICOEUR, Paul. Tempo e narrativa - Tomo III, op. cit., p. 198.

${ }^{26}$ SCHMIDT, Siegfried J. Sobre a escrita de histórias da literatura. Observações de um ponto de vista construtivistas, op. cit.

27 RICOEUR, Paul. Tempo e narrativa - Tomo III, op. cit.
} 
Não tiveram eles ampla divulgação, seus livros não existem nas melhores bibliotecas do Estado; sua vida e seu merecimento intelectual, a ação que desenvolveram, as influências que determinaram, são cousas ignoradas pela maioria dos leitores. ${ }^{28}$

Essa asserção é tão verdadeira nos dias atuais como era quando Cesar escreveu sua História da Literatura do Rio Grande do Sul (1956). Daí a importância de um arquivo como o da revista Província de São Pedro, pois, quando se extrai de um arquivo a citação de um texto ou de um autor do passado significa, não só trazê-lo para o presente, mas "infundir outra vida ao que foi citado". ${ }^{29}$ Uma "vida" que permitirá a construção de uma ponte capaz de dificultar apagamentos, com um corpus apto a fornecer respostas mais convincentes a pergunta "do que é escrever entre nós".30

No primeiro número (julho de 1945) da Província já podemos encontrar um longo texto escrito por Azambuja. Trata-se de um ensaio intitulado "História e Imaginação". Nele, o autor trabalha com o conceito de que os vazios da história, muitas vezes, precisam ser preenchidos pela imaginação. "Como reconstruir uma época remota, uma civilização desaparecida, sem um pouco de imaginação?", ele pergunta. ${ }^{31}$ Explica que há algum tempo críticos e filósofos têm travado uma guerra contra a história e os historiógrafos por conta da incerteza e insegurança de seus métodos. Esses "escritores cépticos" e "filósofos desiludidos", segundo ele, alegariam que os erros cometidos por conta dessas incertezas impediriam a história de converter-se em uma ciência.

Darcy Azambuja, em seu ensaio, defende um ponto de vista diferente. Para ele, a ideia da exatidão total é uma impossibilidade e, desde que se consigam aparelhos mais perfeitos, até mesmo as leis da ciência seriam apenas uma aproximação da realidade. Azambuja, nesse texto, coloca em dúvida, portanto, as "verdades históricas", optando pelas "verdades narrativas". Logo, não são de estranhar as suas posições sobre o papel da imaginação na narrativa histórica; afinal, segundo ele, "para fazer a história de um simples seixo, seria necessário conhecer todo o mistério do universo."32 Ideia ratificada

\footnotetext{
${ }^{28}$ CESAR, Guilhermino. História da literatura do Rio Grande do Sul (1737-1902), op. cit., p. 20.

${ }^{29}$ MIRANDA, Wander de Melo. Arquivo e memória cultural. In: SOUZA, Eneida Maria de; MIRANDA, Wander de Melo. Arquivos literários. Belo Horizonte: Editora UFMG, 2003. p. 38.

30 Ibidem, p. 39.

31 Província de São Pedro. In: MOTTIN, Antônio João Silvestre et al. Revista Província de São Pedro / 1945/57: catálogo e texto, op. cit.

32 Ibidem.
} 
por Hayden White quando diz que

toda a narrativa não é simplesmente um registro 'do que acontece' na transição de um estado de coisas para outro, mas uma redescrição progressiva de conjuntos de eventos de maneira a desmantelar uma estrutura codificada num modo verbal no começo, a fim de justificar uma recodificação dele num outro modo no final. ${ }^{33}$

Ainda em 1945, Darcy Azambuja publica na Província um conto chamado "Negrinho do Pastoreio" (setembro de 1945). Esse texto já fora publicado, em 1928, em seu livro Contos Rio-Grandenses (Leituras Escolares) e voltaria a aparecer em Coxilhas em 1956. Em março de 1946, Azambuja volta a publicar na Província de São Pedro apresentando o conto "Capivara no Milho" e em junho do mesmo ano publica outro conto chamado "Boi Carreteiro". Essas duas histórias também estariam incluídas em Coxilhas.

Esses três contos ilustram o trabalho de Darcy Azambuja com a temática da Terra e do Homem, apresentando uma técnica narrativa que valoriza a onisciência, o paisagismo e o passado guerreiro do gaúcho. Em contos como "Negrinho do Pastoreio", o "narrador coloca-se como personagem ou testemunha dos fatos narrados e os quadros descritivos desaparecem, dando lugar à utilização abundante do discurso direto." ${ }^{34}$ Já em "Capivara do Milho", Azambuja deixa um pouco de lado a nostalgia tão comum nos contos em que o tema é a campanha, para escrever uma história mais leve e bem-humorada.

Em setembro 1947, publica na revista Província de São Pedro a crônica "Quando Porto Alegre Amanhecia". Essa crônica aparece oito anos depois da publicação do livro de contos A Prodigiosa Aventura (1939) e sete anos depois de Romance Antigo (1940). Nas duas obras, Azambuja demonstra ter abandonado o regionalismo dos primeiros livros, inaugurando um novo ciclo em sua produção literária, voltado para o espaço urbano e para a história. ${ }^{35}$ Nesses textos ele faz uma espécie de inventário de todas as mudanças sofridas por Porto Alegre desde o final do século XIX até o início do século XX: mudanças físicas, sociais e culturais.

Assim, em "Quando Porto Alegre Amanhecia" poderá se perceber a presença de muitos dos elementos existentes em A Prodigiosa Aventura e

\footnotetext{
33 WHITE, Hayden. Trópicos do discurso: ensaios sobre a crítica da cultura, op. cit., p. 115.

${ }^{34}$ BAUMGARTEN, Carlos Alexandre. Darcy Azambuja, op. cit., p. 39.

35 Ibidem.
} 
Romance Antigo. Um procedimento que não se dava pela primeira vez, pois, segundo Baumgarten, "Darcy Azambuja reaproveita em 'Romance Antigo' uma série de informações presentes nos contos de 'A Prodigiosa Aventura'." ${ }^{36}$ No entanto, ao contrário do que ocorreu nos dois livros, na crônica Azambuja exclui todos os componentes ficcionais para se concentrar apenas nos dados históricos. Inclusive, aproveita a crônica para defender uma série de ideias, entre elas de que "Com a cidade começa a história, isto é, começa a humanidade a ter consciência de si mesma." ${ }^{37}$

Darcy Azambuja só voltaria a colaborar com a revista, em 1953, com o conto "Meu Padrinho". Um texto que também reapareceria em Coxilhas. Nele, como em tantos outros contos, o autor conserva muitas das características encontradas no livro Tapera, de Alcides Maya, onde há a utilização de um painel descritivo, rico em adjetivos, sugerindo distanciamento e estaticidade. ${ }^{38}$

Em 1955, Darcy Azambuja encerra sua participação na Província de São Pedro publicando "Arma de Estimação". Esse conto, assim como os anteriores, seria incluído no livro Coxilhas. Aqui, no entanto, a temática não é mais a vida na campanha, mas a oposição campo / cidade. A história foca-se no avanço da estrada de ferro, responsável, não só pela modernização do campo, mas também pela infelicidade que atinge o espaço rural, "já que com ela vem o homem da cidade, portador de distintos valores, que corrompe a campanha com suas ações." ${ }^{39}$

Analisando o material de Darcy Azambuja disponível na Província, pode-se perceber claramente sua trajetória como escritor. Contos com características fortemente regionalistas, apresentando "a mesma nostalgia na observação do espaço, tão comum nos contos de Alcides Maya e Simões Lopes Neto"40 e textos de não ficção (ensaio e crônica) que trazem os resultados de suas pesquisas sobre Porto Alegre e a sua história. A temática rural e urbana constituindo dois eixos de produção reveladores dos caminhos trilhados pelo autor em sua trajetória literária.

Contudo, pode-se notar que o constante reaproveitamento de elementos nas suas narrativas de alguma forma o impediram de romper com os modelos

\footnotetext{
36 Ibidem, p. 55.

37 Província de São Pedro. In: MOTTIN, Antônio João Silvestre; MOREIRA, Alice T. Campos; GLOCK, Flávio Soibelmann et al. Revista Província de São Pedro / 1945/57: catálogo e texto. Porto Alegre, PUCRS, 1999. CD-ROM.

38 BAUMGARTEN, Carlos Alexandre. Darcy Azambuja, op. cit.

39 Ibidem, p. 41.

40 Ibidem.
} 
literários que o antecederam. Fica, então, a pergunta: será que essa atitude conservadora foi a razão para que a sua obra deixasse de ser referendada pelas histórias literárias que vieram mais tarde? Ou ainda, até que ponto um virtual caráter modernista de Darcy Azambuja realmente se consolidou em seu trabalho como escritor?

Enfim, o fato é que há muito tempo uma cortina de silêncio caiu sobre o escritor Darcy Azambuja. Se esse silêncio é merecido ou não, pode ser uma questão para um estudo mais aprofundado. Talvez o importante, nesse momento, seja aceitar que "é nessa brutal capacidade de excluir certos fatos no interesse de constituir outros em componentes de estórias compreensíveis que o historiador exibe seu tato e sua compreensão." ${ }^{11}$ Tato e compreensão que também se revelam na construção de narrativas plausíveis e aceitáveis dos acontecimentos do passado.

\section{CONCLUSÃO}

O primeiro livro de Darcy Azambuja, No Galpão, foi considerado por Guilhermino Cesar como o "momento inaugural"42, do $6^{\circ}$ período (19021925) de sua História da Literatura do Rio Grande do Sul. Conforme Cesar e outros autores - Moreira (1978) e Hamerski (1983) - Darcy Azambuja seria, além de um escritor regionalista, um representante do movimento modernista que se instaurou no Rio Grande do Sul nas duas primeiras décadas do século XX.

No Galpão constituir-se-ia, segundo Artur Hamerski, em uma palavra que "estrutura no tempo, a memória do regionalismo gaúcho, documenta as transformações por que passou o poder econômico, político e cultural no Rio Grande do Sul"43. Alice Moreira avaliou esse livro como uma obra com notável unidade tornando "Darcy Azambuja, na opinião da maioria da crítica, o sucessor de Simões Lopes Neto"44. Por todos esses motivos, e tantos outros que agora não cabe listar, No Galpão recebeu o prêmio na categoria de melhor livro de contos da Academia Brasileira de Letras, em 1925.

${ }^{41}$ WHITE, Hayden. Trópicos do discurso: ensaios sobre a crítica da cultura, op. cit., p. 107.

42 PERKINS, David. História da literatura e narração op. cit.

43 HAMERSKI, Artur. A estrutura metafórica em "No Galpão" de Darcy Azambuja. Dissertação (Mestrado), Pós-Graduação em Letras, Pontifícia Universidade Católica, Rio Grande do Sul, 1983.

${ }^{44}$ MOREIRA, Alice Therezinha Campos. O popular e o literário em Darcy Azambuja, op. cit., p. 8. 
Esses testemunhos levariam a acreditar que se trata de um escritor importante, com espaço garantido na história literária rio-grandense. No entanto, como já foi dito anteriormente, esse não é o caso de Darcy Azambuja. Seu rastro, nos dias de hoje, é frágil, muito frágil. Assim, enquanto Simões Lopes Neto continua sendo leitura obrigatória nas escolas, Darcy Azambuja foi quase que completamente esquecido.

Esse paradoxo chamou a minha atenção desde o início da pesquisa. Mesmo sabendo e reconhecendo a arbitrariedade e a incompletude das histórias literárias, senti-me compelida a tentar entender os motivos por detrás desse esquecimento. Sim, porque motivos existem, mas, como costuma ocorrer, também devem estar debaixo das camadas de silêncio que durante a passagem dos anos acabam sepultando obras, autores e até mesmo seus críticos.

A primeira pista para entender o que pode ter ocorrido encontra-se na introdução do livro de Guilhermino Cesar:

\begin{abstract}
É hábito da historiografia literária registrar os autores adotando como critério de seriação as datas de nascimento. Procedi diferentemente. A data que tomei por base de precedência foi sempre a da obra mais característica; a da estreia, no caso e autores menos significativos. Pareceu-me preferível tal sistema, por motivos óbvios. ${ }^{45}$
\end{abstract}

Ao reler esse trecho é difícil não se perguntar em que categoria Cesar teria incluído Darcy Azambuja: obra mais característica, obra de estreia ou autor menos significativo? O que leva a outra pergunta, feita por Michel Certeau: "o que é uma 'obra de valor' em história?". ${ }^{6}$ Sua resposta é simples e direta:

Aquela que é reconhecida como tal pelos pares. Aquela que pode ser situada num conjunto operatório. Aquela que representa um progresso com relação ao estatuto atual dos 'objetos' e dos métodos históricos e, que, ligada ao meio no qual se elabora, torna possíveis, por sua vez, novas pesquisas. ${ }^{47}$

Nesse sentido, Artur Hamerski, ao analisar No Galpão, defendeu a ideia de que Darcy Azambuja estilizou o passado e o projetou no futuro. Para ele, tratava-se de uma obra que ultrapassava o mundo metafórico, induzindo o leitor a recriá-la. ${ }^{48}$ Do mesmo modo, Alice Moreira, concordando com

${ }^{45}$ CESAR, Guilhermino. História da literatura do Rio Grande do Sul (1737-1902), op. cit., p. 22.

${ }^{46}$ CERTEAU, Michel de. A escrita da história, op. cit. p. 72.

47 Ibidem, p. 72-73.

48 HAMERSKI, Artur. A estrutura metafórica em "No Galpão" de Darcy Azambuja, op. cit. 
Hamerski, via No Galpão um livro que se enquadrava perfeitamente no movimento modernista, ou seja, uma obra voltada para as origens valorizando o homem da terra; um "Homem de poucas palavras, de atitudes enérgicas, de espírito libertário". ${ }^{49}$

No entanto, uma questão retorna: será que o modernismo presente No Galpão se consolidou no restante de sua obra?

Alice Moreira, apesar dos elogios à obra No Galpão, reconheceu que em Coxilhas o escritor pouco acrescentou. Segundo ela, nesse livro Azambuja "retoma os temas da Terra e do Homem, confirmando, apenas, as características apresentadas, fixando e aperfeiçoando o estilo claro e conciso da iniciação literária." ${ }^{50}$ Baumgarten vai ao encontro de Moreira ao dizer que a postura assumida por Darcy Azambuja teve, no mínimo, duas consequências: o envelhecimento precoce de sua obra e o consequente distanciamento de sua ficção em relação à proposta modernista. ${ }^{51}$

Baumgarten, ao identificar a presença de uma dupla narrativa na produção literária de Darcy Azambuja - "ora valoriza a onisciência e o paisagismo, nos moldes característicos da obra de Alcides Maya, ora lança mão do relato dinâmico e do narrador testemunha ou personagem, próprios do modelo simoniano" 52 - considera esse um atestado não do rompimento com os modelos literários anteriores, mas da permanência destes e do seu reaproveitamento na modernidade.

E a palavra-chave é justamente essa, "reaproveitamento". Se forem analisadas apenas as contribuições de Darcy Azambuja à revista Província de São Pedro esse procedimento é evidente. Todos os contos escritos para a revista em 1945, 1946, 1953 e 1955 reapareceriam em Coxilhas, última obra do autor, publicada em 1956. Até mesmo o ensaio de 1945 e a crônica de 1947 são "reaproveitamentos" de outras obras, A Prodigiosa Aventura (1939) e Romance Antigo (1940). Utilizando a definição de Michel Certeau, poder-se-ia dizer que Azambuja, ao longo de seu trabalho como escritor de ficção, apesar do reconhecimento conquistado no início de sua carreira, não representou um "progresso em relação ao estatuto atual dos 'objetos'[...]."53 Aparentemente, toda a sua criatividade ficcional se esgotou em No Galpão.

\footnotetext{
49 Ibidem, p. 45.

50 Ibidem, p. 8.

51 BAUMGARTEN, Carlos Alexandre. Darcy Azambuja, op. cit.

52 Ibidem, p. 38.

53 CERTEAU, Michel de. A escrita da história, op. cit., p. 73.
} 
Quais seriam as possíveis razões para essa atitude?

Talvez, a atividade como jurista e professor ocupasse tanto o seu tempo que escrever ficção tenha sido apenas em um impulso da juventude, sendo rapidamente sobrepujado pela necessidade de escrever sobre o seu trabalho. Parafraseando Guilhermino Cesar, ao se referir a Caldre Fião (1824-1876), pode-se dizer: o jurista Darcy Azambuja matou o contista Darcy Azambuja. Ou, quem sabe, devêssemos, simplesmente, aceitar a posição de Baumgarten ao dizer que "do ponto de vista ideológico sua prosa ficcional pouco evolui em relação à literatura regionalista anterior ao Modernismo." ${ }^{54}$

Qualquer das escolhas levará ao mesmo resultado: Darcy Azambuja encontra-se na categoria de autor modernista sem realmente ter aderido aos ideais desse movimento. Sua obra permaneceu estacionada no tempo, presa a uma visão ideologicamente conservadora e a um conjunto de conceitos gerados na segunda metade do século XIX.

Essa ideia justificaria Guilhermino Cesar quando decidiu não mencionar Darcy Azambuja com a mesma frequência com que citou, por exemplo, Alcides Maya e Simões Lopes Neto. Para Cesar, apenas os dois últimos autores tinham as características que os consagrariam como representantes importantes de uma nova fase ou período da história literária rio-grandense:

Na prosa, retomando o fio da tradição "continentina", Alcides Maya e J. Simões Lopes Neto voltam à campanha, sacodem o "monarca das coxilhas", revolvem o passado rio-grandense, e então, estilizando, afeiçoando, brunindo a prosa, retorcendo o período, - empregando valores estéticos denunciadores do Simbolismo, - provocam o surgimento de um novo tipo de literatura regional. ${ }^{55}$

O mesmo raciocínio pode ser empregado para justificar o silêncio de Guilhermino Cesar para com a revista Província de São Pedro. Ela, apesar de todas as suas qualidades, não teria os atributos que, para Cesar, a diferenciariam como uma publicação comprometida com a "nova geração" regionalista que estava surgindo, característica que, aparentemente, a revista Quixote apresentava.

De qualquer modo, as escolhas do que é dito e, principalmente, do que não é dito, fazem parte do trabalho do historiador. Contudo, como explica Certeau, "a imagem do passado mantém o seu valor primeiro de representar

${ }^{54}$ BAUMGARTEN, Carlos Alexandre. Darcy Azambuja, op. cit., p. 41.

${ }_{55}$ CESAR, Guilhermino. História da literatura do Rio Grande do Sul (1737-1902), op. cit., p. 392. 
aquilo que falta." ${ }^{56}$ A Província de São Pedro e Darcy Azambuja são apenas dois exemplos desse silêncio que muitas vezes se instaura sobre uma obra e/ou um autor. Silêncios que, assim como as omissões, são o resultado de "escolhas que Ihes são anteriores, que não resulta, pois, da observação - e que não são nem mesmo 'verificáveis', mas apenas 'falsificáveis' graças a um exame crítico." ${ }^{57}$

Nesse sentido, dentro dos limites estabelecidos para essa pesquisa, narrei um pouco da história da Província de São Pedro e da participação do escritor Darcy Azambuja, não só nesta revista, mas também dentro do cenário da história literária rio-grandense. Contudo, estou plenamente consciente do caráter provisório e incompleto dessa narrativa, pois como explica Schmidt, uma história literária não pode reivindicar e jamais reivindicará completude e universalidade..$^{58}$ Esse é, sem dúvida, um conceito assustador, pois substitui as certezas de encontrar uma "verdade objetiva", pela incerteza de que a interpretação do "fato histórico" está subordinada a "decisões pessoais". No entanto, são essas decisões que impulsionam a construção de narrativas, transformando o historiador em um contador de histórias que a partir de "explicações plausíveis para corpos de testemunhos históricos descobrem a estória ou o conjunto de estórias contidas implicitamente dentro delas." ${ }^{59}$ Para concluir, volto a parafrasear Guilhermino Cesar dizendo que, esquecer Darcy Azambuja, não o incluir entre aqueles que fizeram a história da literatura no Rio Grande do Sul, isto é o que não me parece justo.

Recebido em: 29 de julho de 2016 Aceito em: 31 de agosto de 2016

${ }^{56}$ CERTEAU, Michel de. A escrita da história, op. cit. p. 92.

57 Ibidem, p. 67.

${ }^{58}$ SCHMIDT, Siegfried J. Sobre a escrita de histórias da literatura. Observações de um ponto de vista construtivistas, op. cit.

59 WHITE, Hayden. Trópicos do discurso: ensaios sobre a crítica da cultura, op. cit., p. 100. 